Euskal ikerketen aldizkaria | Revue d'études basques |

Revista de estudios vascos | Basque studies review

$3 \mid 1998$

Numéro III

\title{
La bataille du Palestrion octobre-novembre 445
}

\section{Renée Goulard}

\section{OpenEdition \\ Journals}

Édition électronique

URL : https://journals.openedition.org/lapurdum/1726

DOI : $10.4000 /$ lapurdum. 1726

ISSN : 1965-0655

Éditeur

IKER

Édition imprimée

Date de publication : 1 octobre 1998

Pagination : 293-297

ISBN : 2-84127-152-8

ISSN : $1273-3830$

Référence électronique

Renée Goulard, «La bataille du Palestrion octobre-novembre 445 », Lapurdum [En ligne], 3 | 1998, mis en ligne le 01 septembre 2010, consulté le 24 février 2022. URL : http://journals.openedition.org/ lapurdum/1726 ; DOI : https://doi.org/10.4000/lapurdum.1726 


\section{Renée GOULARD}

\section{LA BATAILLE DU PALESTRION OCTOBRE-NOVEMBRE 445}

La Province des Neuf Peuples fut au Ve siècle l'une des régions qui constituèrent le royaume aquitanique, pour reprendre l'appellation qu'utilisa Isidore de Séville dans son Histoire des Goths ${ }^{1}$. Le premier roi goth, établi à la demande de l'ordo gallo-romain régional qui redoutait les invasions et bagaudes, fut Théodoric Ier. Il eut un long règne de 33 ans, le plus apprécié de tous parmi les populations locales, et qui devait se terminer par la première grande bataille médiévale, celle que l'on appelle couramment Champs Catalauniques ou Campus Mauriacus, le 20 juin 451, où le roi trouva la victoire et la mort. Mais il avait auparavant livré bien d'autres batailles. Celle du Palestrion par exemple.

Le diplomatie et les guerres de ce roi le conduisirent à rechercher une entente avec les autres peuples nouvellement installés en Occident. Les Suèves de Galice, en voie de conversion au milieu d'un peuple galicien d'un catholicisme austère et pointilleux, furent la raison de ses nombreuses interventions outremonts où il finit par marier en 449 l'une de ses filles au roi catholique Réchaire. Les Vandales d'Afrique étaient plus éloignés, mais Théodoric avait marié vers 440 une autre de ses filles au prince Hunéric associé à son père le roi Geiséric ${ }^{2}$. Depuis 440 la paix semblait régner du côté de Rome qui avait essuyé une sérieuse rebuffade devant Toulouse en 439, tandis qu'Aétius le maître des deux milices, praesentalis, patrice depuis 435 , trouvait en son petit Gaudenzius, né d'une princesse balthe sœur de la reine des Goths, un touchant ambassadeur'. L'empereur Valentinien III n'aurait eu aucune importance dans ce concert s'il n'avait accepté l'idée de fiancer l'une de ses filles à Hunéric, déjà pourvu d'une épouse gothe. Y eut-il une révolte nobiliaire en terre vandale? La princesse gothe y joua-t-elle un rôle? Vaines questions pour un prince vandale désireux de nouer une alliance matrimoniale romaine qui ne serait certes pas l'assurance de la paix mais un argument d'intimidation dont il saurait jouer'.

La princesse gothe fut défigurée, et revint à la cour de son père en 443 , le nez et les oreilles coupés. Geiséric le Vandale savait qu'il pourrait y avoir des représailles ${ }^{5}$. Théodoric était certes le plus puissant roi d'Occident, mais oserait-il un geste alors que tout paraissait en paix? Il l'osa, car ni Aétius ni Valentinien ne furent mis dans la balance contre la colère gothique que l'on sait terrible et qui souleva l'indignation des Gaules.

Les Chroniques de Prosper d'Aquitaine (qui s'arrêtent hélas en 444) et d'Hidace de Galice (jusqu'en 468) sont œuvres de Gallo-Romain et d'HispanoRomain, surtout attentifs à Rome. Ils ne regardent les Goths qu'avec mépris et n'imaginent pas qu'ils puissent avoir d'autre ressort d'action que la haine de Rome. Ils sont nos seuls et tout de même précieux observateurs si nous savons lire ce genre de récit. Ces textes d'usage traditionnel et qui sont déjà une forme 
d'histoire, peuvent être mis en parallèle avec une source de nature très différente : la Vie de saint Sever ${ }^{6}$. Texte difficile, mêlant diverses rédactions dont deux sont repérables comme des compositions du $\mathrm{XI}^{e}$ siècle, la troisième du IX ${ }^{\varepsilon}$ siècle : le prince Guillaume Sanche de Gascogne à qui on en donna lecture aux années 970 la disait alors vieille de presque cent ans. A travers la vie de deux hommes, Sever et Sébastien, que les sources mettent en scène, se découvre une page d'histoire illustrée par le combat du Palestrion, sanglant résultat d'une non moins sanglante injure. Deux hommes qu'en apparence tout oppose, l'un est Romain et l'autre Goth, ont pris part à la bataille du Palestrion, puissante forteresse du premier roi goth des Gaules.

Théodoric à la vue de sa fille mutilée songe à punir le Vandale. En 444 un réfugié de Constantinople vient lui demander asile, et c'est à lui qu'il confie la tâche de former l'armée destinée à intervenir contre les Vandales. Il s'agit du comte Sébastien, membre d'une grande famille de noblesse romaine, général ou plutôt amiral réputé, qui fut un temps maître des deux milices en 432-433. En 433, il fut écarté de ses charges et de Rome par la volonté du puissant Aétius et il se rendit au "palais d'Orient". Le basileus Théodose II l'accueillit et lui confia en 440 la charge de repousser l'invasion vandale qui ravageait la Sicile. La seule nouvelle de son intervention fit virer de bord la flotte de Geiséric. Une victoire de prestige. Mais, poursuivi par "des ennemis" dans Constantinople, le comte Sébastien se rend en 444 à la cour de Théodoric et lui demande asile. Il tombe bien. Théodoric lui confie la mission de préparer à Barcelone une flotte d'intervention contre les Vandales. Mais les rumeurs vont vite dans la Mer Intérieure et Geiséric décide de prendre les devants. Sa flotte est prête, et il sait que Théodoric ne peut oublier l'affront ; et le "roi des rois", Attila, qui dans ses Pannonies règne sur divers peuples, le pousse à l'action car lui-même roule dans son esprit des projets d'attaque de l'Ouest selon l'analyse de Cassiodore que reprend Jordanès.

Alors c'est la course des navires vandales vers le Nord; après avoir passé les colonnes d'Hercule, ils remontent le long des côtes de Lusitanie et de Galice où les assaillants enlèvent des familles entières. Mais ce que Geiséric vise ne peut être que la Gothie aquitanique, la série de bases militaires de Théodoric sur le littoral océanique. Ces côtes atlantiques du golfe aquitain sont beaucoup plus fréquentées que l'on ne l'imagine souvent. En 445, les Vandales les parcourent du Sud au Nord. En 464 ce sera le tour d'Aegidius, chef romain des Gaules, de les descendre du Nord au Sud, à partir de la Loire. Partout ces côtes sont défendues, mais Geiséric qu'ont enivré sa prise et son pillage de Carthage en 439, compte sur la rapidité d'une action que personne n'attend, car l'été vient de s'achever et ce n'est plus la saison de la guerre. Or, pour Geiséric, c'est toujours le temps de la guerre, puisqu'il entra en pilleur dans Carthage le XIV des Calendes de Novembre'. Geiséric a atteint l'Adour. Le dénouement est proche. Il aperçoit les forteresses des Goths qui font grandir l'impatience des assaillants "à en perdre la raison" (Jordanès). Lapurdum (Bayonne) a été dépassée, surprise par cette flotte arrivée du Sud dans les brumes de l'automne. Dax n'a pas davantage mis en œuvre ses défenses ou, si elle le fit, ce fut sans succès. Les navires vandales font rame vers le Palestrion.

C'est alors que Sever et sa Vie entrent en scène. Le saint voit, couvrant les eaux de l'Adour en crue, les navires vandales se porter à l'assaut du Palestrion. C'est une ancienne forteresse romaine que les Goths ont organisée selon leur 
technique du baurgs à palissades et tours rondes. Un groupe militaire de vesi ou visi (mot latinisé rendant le weihs gothique qui se prononce "viss"), aristocratie guerrière, est placé sous l'autorité du gouverneur, chef d'armée. Autour d'eux des saïos sont des soldats libres attachés à la forteresse. Des uns aux autres existent des liens, ceux de vassaux (latin commendati traduisant le gothique andbathos) que révèlent les notes d'un juriste prises sur le code perdu de Théodoric I ${ }^{\text {erg }}$. Avant chaque combat les Goths échangent des serments mutuels d'entraide et de courage qui soutiennent le harijs, armée tout à la fois d'un peuple et d'une terre. Cette terre, c'est le royaume aquitanique dont ils ont reçu chacun leur part en échange de leur service armé, terre qu'ils défendent seuls mais pour tous. Comme Lapurdum, le Palestrion n'est pas toujours rempli de sa garnison complète, car les Goths vivent une partie de l'année sur leurs domaines plus ou moins vastes tandis que leurs généralissimes qui dominent toutes les forteresses d'une même province (reiks, devenus ducs) ont un service de gouvernement auprès du roi (thiudans $)^{9}$. Maintenant les récoltes sont faites, les moissons engrangées, les troupeaux rassemblés. Le Palestrion se garnit en prévision des futures campagnes. Les exercices, les armes, le soin des chevaux retiennent dans l'enceinte castrale les effectifs tout autant que la cour du gouverneur. Cette activité incessante a valu son nom grec au Palestrion gothique, ce qui fit de l'Adour l'Alphée, nom dont hérita ensuite l'Ana (devenu aujourd'hui Guadiana). Le Palestrion est rempli de guerriers et ne sera pas surpris par l'arrivée des Vandales comme l'a été Lapurdum.

Le rôle de Sever à Palestrion est celui d'un Goth, guerrier comme les autres. Son nom pourtant dénote une particularité. Il n'est pas "arien" ("homéen" serait plus juste) comme la majorité des Goths, mais catholique et a pour patron l'un des martyrs les plus connus du monde goth de Dacie-Mésie dans les dernières décennies du IV $V^{c}$ siècle $^{10}$. Il aurait eu sur le gouverneur et aussi sur l'ensemble de la militia du Palestrion une influence certaine, au point d'obtenir leur conversion. Ce qui fit de cette place forte de la puissance gothique un haut lieu du catholicisme, situation inhabituelle. Les provinciaux eux-mêmes, c'est-à-dire les habitants de la région, affluèrent nombreux au Palestrion, certains comme soldats, d'autres comme employés de la cour du gouverneur, et tous formaient une population unie. Le portrait est-il poussé ? Non, car il correspond tout à fait à ce que nous savons de Théodoric I ${ }^{\text {er }}(418-451)$ auteur d'un code apaisant entre les communautés, mais surtout qui a lui-même appelé des catholiques dans son entourage, comme saint Orens d'Auch qui fut en 439 son ambassadeur de paix auprès du général romain Litorius qui assiégeait Toulouse. Orens joignit l'ambassade d'ardentes prières pour la victoire des Goths et la libération de Toulouse. Plusieurs sources évoquent une conversion du roi au catholicisme à la fin de sa vie, ce qui n'était pas, évidemment, du goût de tous les Goths et qui reste une exception parmi les rois balthes des Gaules ${ }^{11}$.

Le Palestrion est paré pour la guerre contre \'offenseur, l'assaillant et l'hérétique vandale, et le combat qui se prépare sera sans merci. La direction des opérations contre les Vandales est confiée au généralissime Sébastien qui n'avait plus de raisons de rester à Barcelone et qui a cheminé avec son armée vers la forteresse des Neuf Peuples à travers les cols pyrénéens tenus par les Goths ${ }^{12}$. Les Goths lancent du haut de la place forte leur formidable cri de guerre, célèbre depuis les batailles des Saules et d'Andrinople où ils défirent les forces impériales, cri d'origine scandinave ou celte comme le chant de guerre qui le suit mais 
que tous les hommes de cette armée, depuis longtemps venus de toutes parts, ont fait leur et qui ne sera proscrit qu'au VII ${ }^{e}$ siècle.

Sever combat parmi les autres mais trouve la mort en assurant la victoire $\left(1^{\text {tr }}\right.$ novembre). Sa réputation de sainteté et de bravoure a permis de considérer sa mort venue du glaive de l'hérétique comme un martyre. La bataille fut gagnée, les Vandales lâchèrent prise, repartirent vers l'Océan ou se dispersèrent. La victoire accomplie, Sébastien, qui était catholique, construisit autour du tombeau du saint une église où de riches colonnes de marbre étaient constellées de clous d'or et d'argent. Le Palestrion devait plus tard prendre le nom de Saint-Sever, et le saint fut réputé comme le défenseur de toute agression à cette terre et à l'Église. Il venait de défendre le royaume du côté du Sud-Ouest tandis qu'Attila se préparait à franchir le Rhin, en apparence loin du royaume aquitanique, mais Théodoric sut très vite que le Sud était sous sa menace lorsqu'il atteignit Orléans. Un étau avait été prévu pour enserrer les Gaules. Le Palestrion avait d'ores et déjà empêché qu'il puisse se refermer.

Bataille ignorée des historiens trop attentifs à Rome, trop enclins à la critique éperdue des sources anciennes, trop méprisants à l'égard des pieuses légendes des saints, la bataille du Palestrion en 445 est une page d'histoire du pays des Neuf Peuples en leurs temps gothiques. Bataille salvatrice d'un royaume que l'on n'a pas le droit d'appeler "royaume de Toulouse", parce que trois résidences royales au moins ont abrité ses rois et sa cour : Toulouse, Bordeaux, et Aire-sur-l'Adour qui dut en partie la quiétude de ses jours à la protection du Palestrion.

\section{Renée GOULARD}

Université de Paris IV-Sorbonne 


\section{NOTES}

1. Isidore de Séville, Historia Gothorum, éd. Th. Mommsen M.G.H., A.A. t. XI, 2, p. 277 , Berlin 1944. Sur la lecture des textes contemporains : Renée Goulard, Les Goths, Paris-Biarritz 1998. Le plus beau récit du Campus Mauriacus est incontestablement celui de Jordanès L. XXXV à XLIII de l'édition citée ciaprès.

2. Sur l'ensemble de la situation, voir l'ouvrage récent que nous venons de citer et les sources: Hidace, Chronique, éd. (sous le nom Hydace) A. Tranoy, Sources chrétiennes n²18, Paris 1974, 2 vol. Prosper d'Aquitaine, "Chronica Prosperi Tironis" éd. Th. Mommsen, M.G.H., A.A. t. IX, Chronica Minora, Berlin 1892. Le Comte Marcellin, Chronicon, éd. J.P. Migne, t. 51, Paris 1846. Chronica Gallica, éd. TH. Mommsen, M.G.H., A.A., t. IX, Berlin 1892. Cassiodore/Jordanès, Getica, éd. O. Devilliers, Histoire des Goths, Paris 1995.

3. Mérobaudes, Panégyrique l d'Aétius, éd. F. Vollmer, Fl. Merobaudis quae supersunt, M.G.H., A.A. t. XIV, Berlin 1905.

4. H. Wolfram, Les Goths, Paris 1990.

5. Jordanès, op. cit. L. XXXVI.

6. A.D. des Landes H 14, copie d'Abadie de 1580 de plusieurs textes constituant l'histoire de l'abbaye de Saint-Sever. Sa lecture peut être vérifiée par la publication de P. de Marca, qui n'édite cependant que la Vita. Abadie ne fournit pas toujours une excellente lecture. On retient parmi les trois récits de la vie du saint la Vie $\mathrm{n}^{\circ} 3$ composée au IX $\mathrm{X}^{\circ}$ siècle, $\mathrm{f}^{\circ} 23$ rouge. Le récit des miracles commence au $\Upsilon^{\circ} 38$ rouge. Ed. Acta Sanctorum Ordinis Sancti Benedicti, Novembre t. 1 p. 211.

7. Quodvultdeus, De tempore barbarico, éd. Patrologiae Supplementum, t. III, Paris 1963.

8. "Fragmenta Gaudenziana", éd. P. Zeumer, M.G.H., Leges t. 1, Leges Visigothorum, p. 469-472.

9. La langue gothique de la fin du IVème siècle se déduit de la traduction de la Bible gothique rédigée par Ulfila vers 380 dont on ne possede que des fragments. Tous les registres de la parole n'y sont pas représentés. La langue d'origine scandinave est déjà très marquée par des emprunts au celte, à l'iranien, au grec et au latin. On peut lui joindre des skeireins, commentaires de la Bible, et quelques lignes d'un calendrier gothique. L'écriture gothique a son alphabet particulier créé par Ulfila, inspiré des runes, des caractères grecs et latins. Un manuscrit se trouve à l'Université d'Upsal en Suède (codex argenteus).

10. La passion de Sever, martyrisé à Adrianopolis et décapité vers 380 est liée à celle des 38 martyrs de Philippopolis selon les synaxaires byzantins. Sever d’Orient est fêté le 23 Août. Il a laissé son nom à au moins deux autres martyrs du $V^{e}$ siècle chez les Neuf Peuples.

11. "Vita Sancti Orienti". ¿d. Acta Sanctorum Ordinis Sancli Benedicti, Mai, t.1 p.63. Grégoire de Tours, Historiarum Decem Libil, Livre II, éd. R. Latouche, Paris 1963.

12. Mérobaudes, Panégyrique II d'Aétius, éd. cit., la bataille du mons Colubrarium et la paix de 439. 